\title{
Spectrum of anxiety and depression reported in reproductive-aged women diagnosed with gynaecological disorders at a tertiary healthcare facility in Ghana
}

\author{
Esther Eshun Oppong ${ }^{1}$, Ernest Obese ${ }^{1}$, Robert Peter Biney ${ }^{1 *}$, Pearlmond Agbalekpor², \\ Priscilla A. Hanson ${ }^{2}$, Maame Y. A. Aboagye ${ }^{1}$, Emmanuel A. Adakudugu', Madison Adanusa ${ }^{3}$, \\ Richard Pinkrah ${ }^{3}$, Anasthasia O. Adomah ${ }^{4}$, Silas A. Osei ${ }^{1}$, Elizabeth N. Oge ${ }^{2}$, \\ Mary A. Agbenyeku², Elvis O. Ameyaw ${ }^{1}$
}

\begin{abstract}
${ }^{1}$ School of Pharmacy and Pharmaceutical Sciences, University of Cape Coast, Cape Coast, Ghana ${ }^{2}$ Department Biomedical Science, School of Allied Health Sciences, College of Health and Allied Health Sciences, University of Cape Coast, Cape Coast, Ghana

${ }^{3}$ Directorate of University Health Services, University of Cape Coast Hospital, Cape Coast, Ghana

${ }^{4}$ School of Nursing and Midwifery, University of Cape Coast, Cape Coast, Ghana
\end{abstract}

Received: 16 June 2021

Accepted: 12 July 2021

*Correspondence:

Dr. Robert Peter Biney,

Email: robert.biney@ucc.edu.gh

Copyright: (C) the author(s), publisher and licensee Medip Academy. This is an open-access article distributed under the terms of the Creative Commons Attribution Non-Commercial License, which permits unrestricted non-commercial use, distribution, and reproduction in any medium, provided the original work is properly cited.

\begin{abstract}
Background: Patients with gynaecological disorders often suffer from psychological disorders including anxiety and depression. Although depression and anxiety have been studied in Ghana, data regarding the prevalence of these disorders in patients with gynaecological disorders is non-existent. The aim of the study was to investigate the prevalence of anxiety and depression in reproductive-aged women diagnosed with gynaecological disorders.

Methods: Cross-sectional observational study was conducted at the Gynaecology Clinic of Korle-Bu Teaching Hospital, a tertiary health facility in Accra, Ghana. Patients of reproductive age seeking gynaecological care at the facility from December 2018 to January 2019 were assessed for anxiety and depression using the Generalized anxiety disorder (GAD) questionnaire and the Beck depression inventory (BDI) respectively. Sociodemographic and clinical information was gathered as well.

Results: Of the 120 patients interviewed (mean age $34.33 \pm 0.66$ ), 36.7\% were depressed while $51.6 \%$ were reported anxiety disorders. Patients aged 35-45 years had the highest prevalence of anxiety (24.58\%) and depression (29.18\%). Again, prevalence rates were highest among respondents with senior high school as the highest educational qualification, (anxiety (22.15\%); depression (24.20\%). Patients suffering from pelvic floor disorder recorded the highest prevalence of anxiety $(11.40 \%)$ and depression $(13.77 \%)$. There was a significant association between depression and gynaecological disorders $\left[\chi^{2}(25)=53.915, \mathrm{p}=0.001, \mathrm{CI}=95 \%\right]$, but there was not enough evidence of an association between anxiety and gynaecological disorders $\left[\chi^{2}(15)=22.791, \mathrm{p}=0.089, \mathrm{CI}=95 \%\right]$.

Conclusions: Anxiety and depression are prevalent amongst women in their reproductive age diagnosed presenting with gynaecological disorders and there is a significant association between gynaecological disorders and the prevalence of depression.
\end{abstract}

Keywords: Gynaecological disorders, Depression, Anxiety, Psychological disorder 


\section{INTRODUCTION}

Gynaecological disorders are diseases of the female reproductive system that endanger the woman's health, sexual function, and infertility. ${ }^{1}$ Common gynaecological disorders such as abnormal vaginal bleeding, uterine fibroids, etc. are also associated with complications of early pregnancy and contraceptive issues. Gynaecological disorders are also associated with high stress and adversely impact the quality of life and psychological well-being of the affected women. ${ }^{2}$ The psychological effect depends on how severe the condition is and how much the symptoms interferes with social and occupational activities. ${ }^{2-3}$

Depression and anxiety are by far the most common psychological disorders in the general population worldwide. ${ }^{4}$ They often manifest as persistent sadness, feelings of hopelessness, guilt, worthlessness, helplessness, loss of interest in pleasurable activities, difficulty concentrating, remembering, and making decisions, and in some cases insomnia, low appetite, and weight loss. ${ }^{5}$ These symptoms are triggered by biopsychological factors, including stressful early life events, physical conditions environmental exposure, side effects of some mediations, diet, genetics, and chemical changes in the brain. ${ }^{6}$

Although depression and anxiety are major causes of male and female impairment, the burden on females is $50 \%$ higher than males. Women are more vulnerable than men to depression and anxiety, with a lifetime prevalence of $21.3 \%$ compared to $12.7 \%$ for men. ${ }^{7-8}$ They are the leading cause of disease burden in women worldwide. ${ }^{9}$ Despite the impact of this on women, the prevalence and consequences of depression and anxiety in women with gynaecologic disorders are understudied although gynaecological disorders affect a large proportion of females of reproductive age. Recent reports in South East Asia predict very high rates of depression and anxiety among patients who were attending a gynaecological clinic versus a general medical clinic. ${ }^{10}$ However such reports are scanty in Africa and largely non-existent in Ghana. With few clinicians and trained researchers, receiving a diagnosis in Ghana can be difficult. This, as well as the accompanying challenges of high rates of diabetes, cardiovascular diseases, infertility, obesity, may contribute to women with gynaecological disorders having increased rates of depression and anxiety.

The aim of the study was to investigate the spectrum of reports of anxiety and depression among reproductiveaged women presenting with gynaecological disorders at the Korle-Bu Teaching Hospital Accra, Ghana.

\section{METHODS}

\section{Study design and sample framing}

The Greater Accra region is one of the administrative regions, and it is bordered on the north by the Eastern
Region, on the east by the Volta Region, on the south by the Gulf of Guinea, and the west by the Central Region. It is the smallest region in Ghana with a total area of $420 \mathrm{~km}^{2}$ and is made up of 16 districts. ${ }^{11}$

The study was conducted at the Gynaecology Clinic of the Korle-Bu Teaching Hospital, which is one of the public tertiary hospitals in the southern part of Ghana, located in the Accra Metropolitan District. The hospital is the largest tertiary referral high-risk obstetric unit in Ghana with about 20,000 gynaecological conditions reported during the study period. Accra, which is the capital city of Ghana, covers an area of about $225.67 \mathrm{~km}^{2}$ with an estimated population of $2,052,341$ by the 2010 Population and housing census. ${ }^{11}$

The cross-sectional observational study consisted of female patients aged 18-45 years seeking gynaecological care from the Korle-Bu Teaching Hospital, Accra, Ghana between December 2018 and January 2019. Participants were recruited during hospital visits and screened for anxiety and depression symptoms using the GAD and the BDI questionnaires respectively. Patients with observable psychiatric or neurological disorders (dementia or psychosis) were excluded.

The prevalence of gynaecological conditions in Ghana has been estimated to be $0.7 \% .^{11}$ Using the formula by Ojewola et al (2017),

$$
N=\frac{z^{2} p d}{d^{2}}
$$

where $\mathrm{N}=$ sample size, $\mathrm{p}=$ prevalence of gynaecological conditions (0.7), $\mathrm{z}=$ level of significance at 95\% CI (1.96).

$$
q=1-p=0.3
$$

and $d=5 \%$ at $95 \%$ confidence interval; sample size of 120 participants was estimated for this study. The study protocol was approved by the Korle-Bu Teaching Hospital Institutional Review Board. Written consent was sought from interested participants after the mode of study was detailed to them. Results were strictly kept confidential.

\section{Inclusion criteria}

All patients seeking gynaecological care at the Gynaecological clinic at Korle-bu Teaching hospital. The willingness to participate was evident upon the completion and signing of the consent by individuals.

\section{Data collection}

After consent was obtained, participants completed the study questionnaire (the GAD and BDI questionnaire) at the gynaecology clinic while waiting to see their health care providers during routine visits. 
Each participant was asked a series of questions covering age, educational level, employment, and marital status and was also asked about their medical or gynaecological history and the availability of healthcare facilities.

A 7-items GAD questionnaire was used to screen for generalized anxiety disorder. The GAD-7 score is calculated by assigning scores of $0,1,2$, and 3 , to the response categories of 'not at all', 'several days', 'more than half the days', and 'nearly every day', respectively. These scores are added and a total score is obtained. Scores of 5, 10, and 15 are taken as the cut-off points for mild, moderate, and severe anxiety, respectively. Anxiety was defined as a GAD score $>10$ indicating at least moderate symptoms of anxiety. ${ }^{12}$ The BDI was used to assess depression in the respondents. The BDI is a 21-questions multiple-choice self-report inventory, composed of items relating to symptoms of depression, both emotional and physical. It is scored on a scale of 0-3 in a list of four statements arranged in increasing severity about a particular symptom of depression. Scores are added for the twenty-one questions by counting the number to the right of each question marked by the patient with 63 being the highest possible final score. Scores ranging from 1-10 are considered normal, 11-16 mild mood disturbance, 17-20 borderline clinical depression, 21-30 moderate depression, 31-40 severe depression and over 40 extreme depression.

\section{Data analysis}

Statistical analyses were performed using SPSS for windows version 25. Exploratory analyses for correlation among the variables were computed using Spearman's correlation. Variables that correlated were further analyzed in a linear regression analysis.

\section{RESULTS}

\section{Patient characteristics}

The respondents constituted mostly adult reproductiveaged women within the 35-45 years age bracket.

They were largely educated $(96.7 \%)$ with $24 \%$ of the respondents with tertiary level education while a majority of the respondents $(49.2 \%)$ had SHS as the highest educational status (Table 1).

Table 1: Age and highest educational level of participants in the study population.

\begin{tabular}{|lll|}
\hline Characteristic & Frequency & Percentage (\%) \\
\hline Age (years) & & \\
\hline $18-24$ & 13 & 10.8 \\
\hline $25-34$ & 48 & 40.0 \\
\hline $35-45$ & 59 & 49.2 \\
\hline Highest educational level & \\
\hline None & 4 & 3.3 \\
\hline Primary & 8 & 6.7 \\
\hline JHS & 24 & 20.0 \\
\hline
\end{tabular}

$$
\begin{array}{lll}
\text { SHS } & 59 & 49.2
\end{array}
$$

\section{Distribution of gynaecological disorders}

A total of $37.5 \%(\mathrm{~N}=45)$ of the gynaecological disorders documented were benign tumours (uterine fibroid and endometrial polyp).

Pelvic floor disorders (pelvic inflammatory disease, cystocele, vaginitis, yeast infection, urine incontinence, endometriosis, and adenomyosis) were also moderately prevalent $21.7 \%(\mathrm{~N}=26)$.

Endocrine gynaecological disorders such as polycystic ovarian syndrome and ovarian cyst and menstrual disorders including amenorrhea, menorrhagia, metrorrhagia, oligomenorrhea, and premenstrual syndrome were all reported by respondents.

Malignant cancers accounted for $5 \%$ of respondents (Table 2).

Table 2: Spectrum of gynaecological disorders of participants in the study population.

\begin{tabular}{|ll|}
\hline Gynaecological disorders & Percentage (\%) \\
\hline Benign tumours & \\
\hline Uterine fibroid & 34.2 \\
\hline Endometrial polyp & 3.3 \\
\hline Pelvic floor disorders & \\
\hline Yeast infections & 9.8 \\
\hline Endometriosis & 9.2 \\
\hline Pelvic inflammatory disease & 5 \\
\hline Cystocele & 4.2 \\
\hline Others & 2.4 \\
\hline Endocrine and menstrual disorders \\
\hline Menstrual disorders & 11.6 \\
\hline PCOS & 10.8 \\
\hline Ovarian cyst & 1.7 \\
\hline Malignant cancers & \\
\hline Ovarian cancer & 1.7 \\
\hline Cervical cancer & 1.7 \\
\hline Endometrial cancer & 0.8 \\
\hline Other disorders & 15 \\
\hline
\end{tabular}

\section{Prevalence of anxiety and depression}

Of the 120 participants, $23.3 \%$ had no symptoms of depression and met the criteria for no depression disorder. However, $2.5 \%$ reported extreme depression while $8.3 \%$ had severe depression.

The majority of respondents exhibited either moderate depression $(25.8 \%)$ or had mild mood disturbances $(25.0 \%)$. Borderline clinical depression was reported in some patients $(15.0 \%)$ (Table 3 ).

Regarding anxiety, $21.7 \%$ of respondents were normal and did not meet the criteria for a diagnosis of anxiety disorder. 
The majority of patients however reported moderate anxiety $(28.3 \%)$ or mild anxiety $(26.7 \%)$ (Table 4$)$.

\section{Distribution of depression and anxiety according to age, level of education, and gynaecological disorders}

A total of $36.7 \%$ of women surveyed were depressed while this figure was $51.6 \%$ in anxiety. In both anxiety and depression, respondents in the age bracket of 35-45 years had the highest prevalence (anxiety $=24.58 \%$, depression $=$ $29.18 \%$ ). The prevalence was more than 1.25 times that recorded in participants aged 24-35 years and over 5 times the prevalence reported among 18-24 years old. Considering the highest educational level attained, respondents with SHS as the highest qualification had the highest prevalence in both anxiety and depression (22.15 and 24.30 respectively) followed by those with JHS qualification. Prevalence among tertiary education level participants was significantly lower than SHS and JHS counterparts in both depression and anxiety. In the same regard, women with pelvic floor disorders exhibited the highest prevalence in both anxiety and depression $(11.3 \%$ and $13.44 \%$ respectively). Anxiety status did not differ significantly between adult menstrual-aged women $(25.41 \%)$ premenopausal women $(24.58 \%)$. Overall, the incidence of anxiety was higher than depression across all gynaecological disorders evaluated in the study.

\section{Statistical analysis}

There was no correlation between BDI scores and age, educational qualification. However, there was a weak positive correlation between BDI and the type of gynaecological disorder (Spearman's rho $=0.235 ; \mathrm{p}=0.01$ ).

The strongest correction observed among the variables was between BDI and GAD scores (Spearman's rho=0.623; $\mathrm{p}<0.001)$. GAD scores however did not correlate with any other variable. Linear regression analyses of BDI score on GAD score revealed an $\mathrm{r}^{2}$ of $0.332(\mathrm{y}=\mathrm{BDI}=\mathrm{GDI} \times 1.016+7.646 ; \mathrm{F}<0.001)$.

Table 3: Prevalence of depression.

\begin{tabular}{|lll|}
\hline Symptom criterias & BDI score & Percentage $(\%)$ \\
\hline $\begin{array}{l}\text { No depression } \\
\text { Mild mood } \\
\text { disturbances }\end{array}$ & $0-10$ & 23.3 \\
\hline $\begin{array}{l}\text { Borderline clinical } \\
\text { depression }\end{array}$ & $17-16$ & 25.0 \\
\hline $\begin{array}{l}\text { Moderate } \\
\text { depression }\end{array}$ & $21-30$ & 15.0 \\
\hline Severe depression & $31-40$ & 25.8 \\
\hline Extreme & $>40$ & 2.5 \\
\hline
\end{tabular}

Table 4: Prevalence of anxiety in respondents.

\begin{tabular}{|lll|}
$\begin{array}{l}\text { Symptom } \\
\text { criterias }\end{array}$ & GAD score & Percentage (\%) \\
\hline No anxiety & $0-4$ & 21.7 \\
\hline
\end{tabular}

\begin{tabular}{|lll|}
\hline Mild anxiety & $5-9$ & 26.7 \\
\hline Moderate anxiety & $10-14$ & 28.3 \\
\hline Severe anxiety & $\geq 15$ & 23.3 \\
\hline
\end{tabular}

Table 5: Anxiety and depression status across age, educational and gynaecological status-based disorders groupings in the study population.

\begin{tabular}{|lll|}
\hline $\begin{array}{l}\text { Characteristics } \\
\text { Age (years) }\end{array}$ & Anxiety (\%) & Depression (\%) \\
\hline $18-24$ & 5.61 & 2.68 \\
\hline $25-34$ & 19.80 & 18.13 \\
\hline $35-45$ & 24.58 & 29.18 \\
\hline Educational level & & \\
\hline None & 1.63 & 1.10 \\
\hline Primary & 1.48 & 3.85 \\
\hline JHS & 10.50 & 14.30 \\
\hline SHS & 22.15 & 24.20 \\
\hline Tertiary & 12.43 & 6.50 \\
\hline Gynaecological disorder & \\
\hline $\begin{array}{l}\text { Benign tumours } \\
\text { Pelvic floor } \\
\text { disorder }\end{array}$ & 10.35 & 4.35 \\
\hline $\begin{array}{l}\text { Endocrine } \\
\text { disorders }\end{array}$ & 11.40 & 13.77 \\
\hline $\begin{array}{l}\text { Menstrual } \\
\text { disorders }\end{array}$ & 7.98 & 9.37 \\
\hline \begin{tabular}{l} 
Malignant cancers \\
\hline \begin{tabular}{l} 
Other disorders \\
\hline
\end{tabular}
\end{tabular} & 3.40 & 1.62 \\
\hline
\end{tabular}

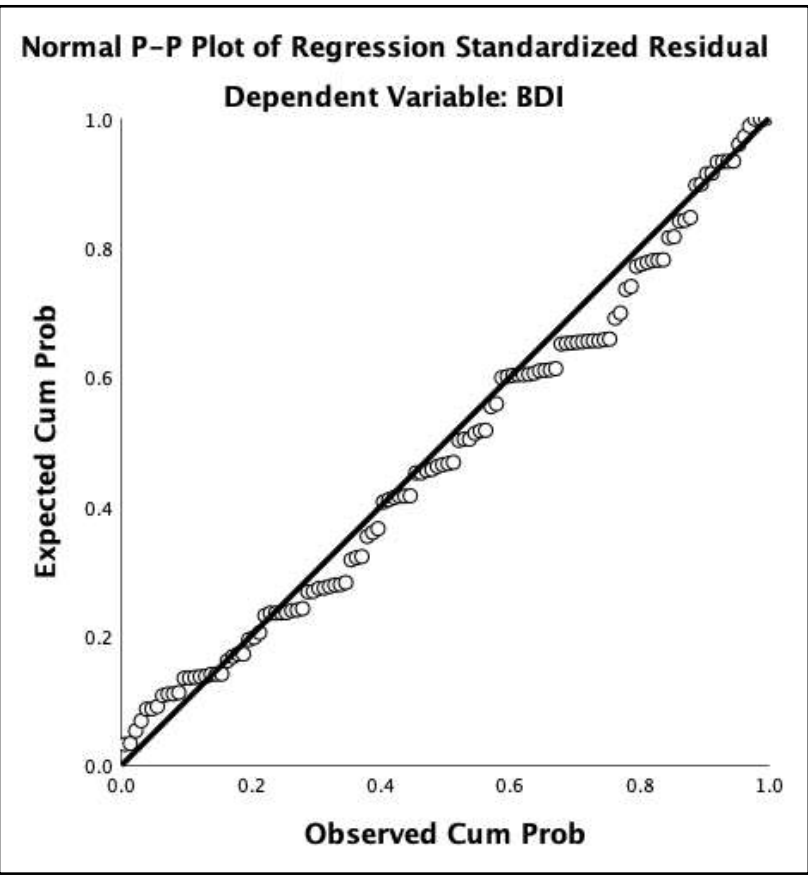

Figure 1: Normal P-P plot of the regression of BDI scores on GAD scores.

\section{DISCUSSION}


The study revealed a significant level of anxiety and depression in the studied population. The few studies that have investigated problems of psychiatric morbidities in gynaecology outpatient clinics have found that on average about $50 \%$ of women who seek gynaecological care are estimated to exhibit higher levels of psychiatric morbidities than those found in studies of other general hospital outpatient clinics. ${ }^{10}$ In this study, $51.6 \%$ of the women reported anxiety (Table 4), and 36.7\% suffered from depression upon evaluation (Table 3).

To begin with, in this study, the age range 35-45 years had the highest percentage $(49.2 \%)$ of participants, indicating that reproductive-aged women were at increased risk of getting gynaecological disorders as they grow older. In addition to this, age ranges of 25-34 equivalent to $40 \%$ were the next highest, followed by age ranges of 18-24 comparable to $10.8 \%$ which was the least (Table 1). There was a predominance of anxiety symptoms in adult menstrual-aged women. Women aged 35-45 years had lower anxiety levels compared to their counterparts in the 18-34 years group. Comparatively higher prevalence of anxiety has been reported in young people. ${ }^{13}$ Our study also revealed $36.7 \%$ being depressed with the majority being in the 35-45 years bracket which is in support of earlier works that depression as being most common in the 20-40 years age group. ${ }^{14}$ It has been suggested that because apart from the fact that women in this age group are prone to gynaecological disorder, they are most likely to be experiencing other social stressors such as academic stress, unemployment, drug abuse, marital stress, political violence, etc., all of which can contribute to the high prevalence of depression among women in these age group.

Secondly, the reproductive-aged women with no educational background do not visit the hospitals for treatments and tend to use other means such as prayer camps, herbalists, etc, believing that there is the existence of a supreme being who would heal them of their disease. ${ }^{15}$ This contributed to them having the least percentage (3.3\%) among all the women visiting the Gynaecology clinic at Korle-Bu Teaching Hospital, Accra Ghana. The educational background with the highest incidence was recorded in Senior High School levers and the next highest percentage of women who had tertiary education. This indicates that education plays a significant role in the health-seeking behaviour of women as reported by some studies. ${ }^{16,17}$ Likewise, the educational background group with the highest recorded depression and anxiety was that of SHS. This contradicts the findings of Fulvio et al that higher educational level, or the factors that are reflected by higher education, may protect against depression, and the protective effect seems to accumulate throughout life. ${ }^{18}$ Nevertheless, because more participants were in the no depression group $(10.92 \%)$ than in the depression group $(6.55 \%)$ for tertiary, our results support the findings of Bjelland and colleagues about the notion that higher education protected persons against depression.
Next, the diagnosis with the highest percentage and frequency was the benign tumours which comprised uterine fibroids and endometrial polyps, from this study. These findings also support Farris et al who stated that uterine fibroids are usually the most common presenting gynaecological disorder. ${ }^{19}$

In the current study, women suffering from pelvic floor disorders had the highest recorded depression. It has been suggested that there is a correlation between depression and pelvic floor disorders. ${ }^{20}$ It is thus recommended that women with PFD be given additional attention from their health care providers owing to their high probability of suffering from depressive disorders. In general women with gynaecological disorders reported higher rates of depression. This implies that gynaecological conditions such as miscarriage, severe anaemia resulting from menstrual morbidities, and ectopic pregnancy impact negatively on wellbeing and thus it was not surprising that gynaecological disorders correlated strongly with depression scores. ${ }^{21}$ Attempts must be made to strengthen social support for these women to reduce the burden of depression among them.

Anxiety levels were highest in women with pelvic floor disorders $(11.40 \%)$, followed by those with benign tumours (10.35\%), gynaecological endocrine disorders, and menstrual irregularities group $(7.98 \%)$ each of which is moderately high. Nonetheless, there was no significant association between reproductive-aged women diagnosed with gynaecological disorders and their anxiety status. Although menstrual problems are associated with impaired physical and social functioning, stress, and multiple psychological symptoms, including depressive and anxious symptoms our study indicated a prevalence of only $1.26 .^{22}$ Additionally, our study indicated that women with endocrine disorders reported higher rates of depression. Findings from our study and previous reports indicate impairment of psychological function in women with PCOS, particularly for women reporting infertility. ${ }^{23}$ Some women attribute their mood profiles to having PCOS or ovarian cyst. ${ }^{24}$ We also report that fewer women with benign tumours were depressed. This could be as a result of the fact that patients with cancer diagnosis/cancer scares might have benefited from counselling services about their disorders and thus less likely to worry about it compared to the others who not have had any benefit of counselling.

\section{CONCLUSION}

The findings of the study reveal a high rate of anxiety and depression in the women seeking gynaecological care from the Korle-Bu Teaching Hospital Accra, Ghana. There is a significant association between gynaecological disorders we reproductive-aged women and depression but could not establish an association between anxiety and gynaecological disorders among women.

\section{ACKNOWLEDGEMENTS}


We appreciate all laboratory technologists of the School of Pharmacy and Pharmaceutical Sciences, UCC.

Funding: No funding sources

Conflict of interest: None declared

Ethical approval: The study was approved by the Institutional Ethics Committee

\section{REFERENCES}

1. WHO. Women's health, 2020. Available at: https://www.who.int/healthtwomenhealth/. Accessed on 08 June 2021.

2. Grow S, Neville S, Alpass F, Rodgers V. Loneliness and self-reported health among older persons in New Zealand. Australas J Ageing. 2012;31(2):121-3.

3. Garabiles MR, Lao CK, Yip P, Chan EWW, Mordeno I, Hall BJ. Psychometric Validation of PHQ-9 and GAD-7 in Filipino Migrant Domestic Workers in Macao (SAR), China. J Pers Assess. 2020;102(6):83344.

4. Mohammadi TM, Sabouri A, Sabouri S, Najafipour H. Anxiety, depression, and oral health: A populationbased study in Southeast of Iran. Dent Res J. 2019;16(3):139-44.

5. Elroy E, Fearon P, Belsky J, Fonagy P, Patalay P. Networks of Depression and Anxiety Symptoms Across Development. J Am Acad Child Adolesc Psychiatry. 2018;57(12):964-73.

6. Laganà AS, Rosa VL, Rapisarda AMC, Valenti G, Sapia F, Chiofalo B, et al. Anxiety and depression in patients with endometriosis: impact and management challenges. Int J Womens Health. 2017;9:323-30.

7. Carroll AJ, Jaffe AE, Stanton K, Guille C, Lazenby GB, Soper DE, et al. Program Evaluation of an Integrated Behavioral Health Clinic in an Outpatient Women's Health Clinic: Challenges and Considerations. J Clin Psychol Med Settings. 2020;27(2):207-16.

8. Kuehner C. Why is depression more common among women than among men? Lancet Psychiatry. 2017;4(2):146-58.

9. Ngasa SN, Sama CB, Dzekem BS, Nforchu KN, Tindong M, Aroke D, et al. Prevalence and factors associated with depression among medical students in Cameroon: a cross-sectional study. BMC Psychiatry. 2017;17(1):216.

10. Khalid SS, Huma S, Hotiana UA, Tariq M, Nadeem M. Prevalence of Anxiety and Depression amongst Patients presenting with Non-inflammatory Vaginal Discharge. J Saidu Med Colleg. 2020;10(1).

11. Ghana Health Service. The Health System in Ghana, Facts and Figures. Ghana Health Service, 2018. Available at: https://assets.publishing.service.gov.uk/government/u ploads/system/uploads/attachment_data/file/812958/ Ghana_-_Medical_and_Healthcare. Accessed on 08 June 2021 .
12. Kroenke K, Spitzer RL, Williams JB, Monahan PO, Löwe B. Anxiety disorders in primary care: prevalence, impairment, comorbidity, and detection. Ann Intern Med. 2007;146(5):317-25.

13. Mondin TC, Konradt CE, Cardoso TA, Quevedo LA, Jansen K, Mattos LD, et al. Anxiety disorders in young people: a population-based study. Braz J Psychiatry. 2013;35(4):347-52.

14. Talukder US, Uddin MJ, Khan NM, Billah MM, Chowdhury TA, Alam MF, et al. Major depressive disorder in different age groups and quality of life. Bangladesh J Psychiat. 2014;28(2):58-61.

15. Arias D, Taylor L, Atta A, Bradley EH. Prayer Camps and Biomedical Care in Ghana: Is Collaboration in Mental Health Care Possible? PLoS One. 2016;11(9):162305.

16. Magaard JL, Seeralan T, Schulz H, Brütt AL. Factors associated with help-seeking behaviour among individuals with major depression: A systematic review. PLoS One. 2017;12(5):176730.

17. Kifle D, Azale T, Gelaw YA, Melsew YA. Maternal health care service seeking behaviors and associated factors among women in rural Haramaya District, Eastern Ethiopia: a triangulated community-based cross-sectional study. Reprod Health. 2017;14(1):6.

18. Fulvio GT. Sexual minority youth, social connection and resilience: from personal struggle to collective identity. Soc Sci Med. 2011;72(10):1611-7.

19. Farris M, Bastianelli C, Rosato E, Brosens I, Benagiano G. Uterine fibroids: an update on current and emerging medical treatment options. Ther Clin Risk Manag. 2019;15:157-78.

20. Mazi B, Kaddour O, Badr A. Depression symptoms in women with pelvic floor dysfunction: a case-control study. Int J Womens Health. 2019;11:143-8.

21. Gao L, Qu J, Wang AY. Anxiety, depression and social support in pregnant women with a history of recurrent miscarriage: a cross-sectional study. J Reprod Infant Psychol. 2020;38(5):497-508.

22. Bromberger JT, Schott LL, Matthews KA, Kravitz HM, Randolph JF, Harlow S, et al. Association of past and recent major depression and menstrual characteristics in midlife: Study of Women's Health Across the Nation. Menopause. 2012;19(9):959-66.

23. Upadhyaya SK, Sharma A, Agrawal A. Prevalence of anxiety and depression in polycystic ovarian syndrome. Int $\mathbf{J}$ Med Sci Public Health. 2016;5(4):681-3.

24. Audrey S, Procter S. Employers' views of promoting walking to work: a qualitative study. Int J Behav Nutr Phys Act. 2015;12:12.

Cite this article as: Oppong EE, Obese E, Biney RP, Agbalekpor P, Hanson PA, Aboagye MYA, et al. Spectrum of anxiety and depression reported in reproductive-aged women diagnosed with gynaecological disorders at a tertiary healthcare facility in Ghana. Int J Basic Clin Pharmacol 2021:10:1056-61. 